\title{
O imaginário da morte repousante em Hilda Hilst
}

\author{
Enivalda Nunes Freitas e Souza (UFU)
}

\begin{abstract}
RESUMO: A crítica do imaginário estuda a hermenêutica dos símbolos, das imagens e dos mitos no processo da criação literária, vendo neles um esforço poético de resgatar o homem de sua temporalidade. Segundo Gilbert Durand, que elaborou a teoria dos regimes Diurno e Noturno das imagens, o regime noturno promove a junção das forças opostas, o que leva à valorização da morte como intimidade e repouso. Neste sentido, determinados símbolos em Hilda Hilst são reveladores dessa postura de domesticação da morte. Neste trabalho, observamos que os "símbolos da intimidade", como a terra, a casa, o ovo, a barca, são revestidos de uma hierofania que consagra a morte como renascimento.
\end{abstract}

PALAVRAS-CHAVE: Hilda Hilst; Gilbert Durand; Jung; Morte; Símbolos.

ABSTRACT: The criticism of the imaginary studies the hermeneutics of the symbols, the images and the myths in the process of literary creation, seeing in them a poetic effort to rescue the man of his temporality. According to Gilbert Durand, who developed the theory of the schemes Daytime and Night-time of the images, the nighttime scheme promotes the junction of the opposite forces, which leads to the valorisation of death as intimacy and rest. That way, certain symbols in Hilda Hilst show that posture of domestication of death. In this study, we observed that the "symbols of intimacy", such as the land, the house, the egg, the boat, are coated with a hierophany which consecrates death as rebirth.

KEYWORDS: Hilda Hilst; Gilbert Durand; Jung; Death; Symbols.

Em sua monumental obra As estruturas antropológicas do imaginário, Gilbert Durand colhe e organiza imagens de culturas as mais variadas. Ao organizá-las, o estudioso percebe que essas imagens se dividem em dois grandes grupos, pois seguem duas tendências distintas. Durand dá a essas estruturas o nome de regimes, o diurno e o noturno, seguindo a orientação filosófica de observar o universo em composição binária. As imagens desses regimes se apresentam formando uma cadeia simbólica numerosamente reduplicável, isto é, vão formando constelações. Desta forma, o termo estrutura se instaura somente com o sentido de "forma transformável". Ao formar constelações, as imagens seguem uma direção, configurando duas formas de se estar no 
mundo: uma que vê o universo dividido em opostos (morte/vida, bem/mal), caracterizando o Regime Diurno, e outra que procura unir os opostos, promovendo uma harmonização entre eles. Esse Regime é o Noturno, cuja presença da noite favorece a conciliação. Os dois regimes do imaginário, as imagens que os compõem, expressam e dão resposta à maior angústia do homem: sua mortalidade. Pelo trajeto antropológico, isto é, pela conjunção da subjetividade com os elementos sociais e cósmicos, as imagens que o homem produz revelam se sua postura é de combate às forças tenebrosas do tempo ou, se, por antífrase, é atenuante, postura daquele que recebe a ameaça da morte como quem caminha rumo ao aconchego e à intimidade.

\section{O Regime Noturno místico}

O Regime Noturno da imagem, aquele que se esforça por fundir e harmonizar as contradições que envolvem os homens, apresenta-se de forma mística e sintética e, em ambos os casos, trata-se de um mergulho na intimidade na tentativa de alcançar conhecimento.

Segundo Durand, o termo místico deve ser entendido em seu sentido comum, "mais vago e menos científico": "Daremos ao adjetivo místico o seu sentido mais corrente, no qual se conjugam uma vontade de união e um certo gosto da intimidade secreta”. (DURAND: 2001, 269). Marcado pela inversão (a capacidade de transformar símbolos negativos em positivos), o regime noturno místico será regido pelas estruturas do "redobramento e perseverança", e suas conseqüentes "viscosidade e adesividade", além das estruturas do "realismo sensorial" e da "miniaturização". Sobre "redobramento e perseverança", Durand afirma: "Há na profundidade da fantasia noturna uma espécie de fidelidade fundamental, uma recusa de sair das imagens familiares e aconchegantes" (269). Atualmente, não só a crítica psicanalítica admite que um autor trabalha com poucos temas, dedicando-se a modulá-los ao longo de suas produções. De igual forma, é consensual que o autor prima pela eleição de determinados elementos simbólicos.O leitor familiarizado com a obra poética de Hilda Hilst reconhece em seus versos sua fidelidade e predileção por certas imagens, tais como cavalos, tigres, onças, casas, pátios, cama, terra, barcos, e suas constelações simbólicas. 
O redobramento e a perseverança oferecem outra característica: a "viscosidade", a "adesividade", estrutura que confirma a variação temática recaindo sempre sobre um mesmo significado: "Esta viscosidade do tema traduz-se não por uma exata repetição estereotipada de uma interpretação dada, mas por variações temáticas que evidenciam o isomorfismo das interpretações" (270). Aqui, nada mais se tem do que a estrutura do encaixamento: da cama à casa, da casa à terra e da terra ao barco-túmulo. Nestas imagens, Hilda Hilst manifesta sua fidelidade à visão da morte como repouso, quietude, força outrora tenebrosa que se faz amiga e inevitável, portanto, possibilidade de recomeço ou de aquiescente retorno ao estado primitivo das coisas.

O tema da morte está na poesia de Hilda Hilst desde suas primeiras produções: Presságio - poemas primeiros, de 1950; Balada de Alzira, de 1951 e Balada do festival, de 1955. Pode-se dizer que nestes três primeiros livros (reunidos pela Globo em único livro sob o título de Baladas, em 2003), o tema da morte é fruto de uma "filiação poética". Com o tempo, transforma-se em tema afetivo, indissociável da longa experiência poética e dos anos que vão se passando.

Durand avança na percepção da característica da viscosidade e o alça a outros espaços:

"Esta viscosidade manifesta-se em múltiplos domínios: social, afetivo, perceptivo, representativo. Já vimos como a viscosidade do tema era importante, dado que ela dita um pensamento que deixa de ser feito de distinção e passa a sê-lo de variações confusas sobre um único tema” (271).

No domínio social, o artista desta característica é pouco dado a dissociações: gosta de fazer amigos e acolhê-los em sua casa, uma vez que a própria casa passa a ser uma "comunidade", uma "vila" de eleitos, um espaço construído para esse fim. Todos sabemos que Hilda Hilst construiu a Casa do Sol com fim específico de dedicar-se plenamente ao exercício da literatura. A Casa do Sol transformou-se em espaço afetivo de irradiação da cultura e da amizade. Durand sublinha que essa predisposição ao aglutinamento é própria do eufemismo, da antífrase que converte a experiência dolorosa da morte em renascimento:

“a vocação de ligar, de atenuar as diferenças, de subutilizar o negativo pela própria negação é constitutiva deste eufemismo levado ao extremo a que se chama antífrase. Na linguagem mística tudo se eufemiza: a queda torna-se 
descida, a manducação engolimento, as trevas adoçam-se em noite, a matéria em mãe e os túmulos em moradas bem-aventuradas e em berços.” (273)

Por fim, compondo o Regime Noturno místico temos as estruturas do "realismo sensorial" e da "miniaturização". O realismo sensorial é marcado pela vivacidade das imagens: o artista vai além da descrição; sua força imaginativa é capaz de deformar as imagens conhecidas e inaugurar outras; sua criatividade penetra, anima e reabilita as imagens. Por sua vez, a estrutura da miniaturização, ou o processo de gulliverização, apresenta o amor pelo detalhe: "é no Regime Noturno da imagem, pelo jogo dos encaixes sucessivos, que o valor é sempre assimilado ao último conteúdo, ao mais pequeno, ao mais concentrado dos elementos". (276) Ora, certamente são estas duas estruturas as mais indissociáveis da composição poética, pelo poder que tem o poema de revigorar o imaginário, ao inaugurar a cada imagem um sentido novo, e pelo extraordinário poder de captar o macrocosmo com a magia de uma única metáfora.

Em sua obra Literatura e antropologia do imaginário, Maria Zaira Turchi relê os gêneros literários sob a perspectiva das estruturas simbólicas do imaginário e estabelece para o gênero lírico as mesmas noções do regime noturno místico, porque, dentre outras afinidades, o modo de ser do lírico é, em essência, místico, uma vez que ambos revelam o mundo como emoção. Diz a autora

"No lírico e no místico, as ligações e as fusões infinitas são organizadas pela atitude repetidora da consciência, capaz de transformar o ruído do mundo em melodia, reduzindo a distinção entre a palavra e a coisa e buscando o indizível do momento simultâneo da imagem". (2003, 63)

Temos observado que o imaginário da morte em Hilda Hilst obedece ao princípio de eufemização, portanto, está associado ao Regime Noturno místico do imaginário, segundo o qual a tendência do ser humano é exorcizar as forças tenebrosas do tempo não pela antítese polêmica e implacável da separação que caracteriza o Regime Diurno das imagens, mas promovendo a junção das forças opostas, o que leva à valorização da morte. 


\section{Os símbolos da morte repousante}

A obra Da morte. Odes mínimas (2003) representa um esforço da poeta em colocar o sujeito em atitude de enfrentamento com a morte sem a espada na mão. Os elementos simbólicos ali presentes são reveladores de uma postura de domesticação da morte, representada sobretudo pelos animais, símbolos terrificantes por excelência, que surgem dóceis e íntimos: o cavalo infernal converte-se em cavalinha e seu tropel anunciador do momento tenebroso não se ouve, porque seus cascos estão enfaixados. Essa atitude de eufemização da morte vai-se desdobrar ao longo da obra, quando a poeta os abandona em favor dos "símbolos da intimidade", como a casa, a terra, o pátio, a mandala, a barca e o ovo, todos símbolos de uma mesma constelação hierofânica que consagra a morte como renascimento. Essas imagens-símbolos da intimidade expõem o desejo de mergulhar na morte e conhecer o seu mistério; significam valorizar a morte e exorcizar sua presença tenebrosa e terrificante.

Nos poemas que sucedem ao "pequeno bestiário" de abertura, em que ainda se observa uma presença maciça e mais volumosa da morte pela recorrência de animais primitivos como rinoceronte, elefante, malgrado sua domesticação, a morte será vista como recomeço, nascimento e reintegração ao estado primitivo, ou, nas palavras de Freud, restauração de "um estado anterior de coisas". Verificaremos nesses poemas a vontade de união, de penetrar fundo, em gestos que sempre revelam a morte em “desvantagem", porque a esta pertence só um momento, um brevíssimo instante, ao passo que o sujeito-lírico sempre viveu intensamente, como afirma nestes versos:

Imagina-te o que perderás eu que vivi no vermelho Porque poeta, e caminhei A chama dos caminhos Atravessei o sol Toquei o muro de dentro dos amigos.

É com esse mesmo ir mais além, romper as muralhas que guardam a mais secreta intimidade, que a poeta se ampara para reconhecer a morte como companheira, como inferior à força palpitante da vida. Quem foi tão fundo não teme quem se mostra em superfície ou, em profundidade, sempre mascarada, de tal forma que atingi-la é encarar as próprias profundezas e suas origens primordiais. Se a morte é funda, no mais 
profundo do osso, se é torsão de todas as funduras, a poeta também é de fundura de poço, por isso, íntima a pretende, instigando-a: "Dentro do meu ser / afunda-te, / dentro do meu sofrer". Da procura constante pela morte, restaram suas "funduras".

\section{A terra}

O caminhar constante para as profundezas do íntimo leva à elaboração de imagens consteladas que remetem à origem, à segurança, ao renascimento, ao desdobrar-se infinito de imagens de repouso e intimidade que sugerem a eufemização do aspecto tenebroso e irreversível da morte em conforto e quietude. Assim, já no segundo poema aparece a imagem da terra, a matéria/imagem que encerra em sua essência o repouso, a intimidade e a profundidade. No nível do inconsciente, voltar à terra é voltar à mãe, é restabelecer a união primordial, conforme seus versos: "Que eu te conheça lícita, terrena / Que me tomes sem pena, / Mas voluptuosa, eterna / Como as fêmeas da Terra". Grafada com "t" maiúsculo, a terra representa uma morte que se faz fêmea, genitrix; mais do que sepulcro, a terra é berço que embala, colo que acalanta e solo que germina a vida, repondo-a à condição primordial do Princípio absoluto. A morte imaginada como "fêmea" e "terra" é isomórfica da intimidade materna, da promessa do aconchego, certezas que exorcizam a presença terrificante e maléfica da morte. Esse devir é reforçado pela volúpia sagrada que só sabem ter as fêmeas no seu poder de preservação da vida. Logo, morrer assim é uma antífrase da morte, é celebrar a vida.

\section{A casa}

$\mathrm{Na}$ constelação de imagens que projetam a morte na intimidade, a imagem da terra é correlata à imagem da casa que, por sua vez, remete à morada primordial. A imagem da casa, impregnada de convite ao retorno e ao recolhimento, é engenhosamente construída em um poema instigante, do qual cito algumas estrofes:

Lenho, olaria, constróis

Tua casa no meu quintal.

E desde sempre te espio Nova crescendo agora

Nos meus cinqüenta.

E madeirames e telhas 
E escadas, tuas rijezas Vezenquando te volteias

Para que eu não me esqueça Casa e começo, tua cara,

A qualquer tempo te reconheço.

Mesmo para quem concebe a morte como um ato eufemizante das durezas da vida, uma possibilidade de penetrar um mistério inquietante, observar esse incômodo inquilino fazer moradia em seu próprio quintal, sentindo a cada dia a proximidade da construção pronta a ser habitada, não afasta o temor que obriga à vigilância. Afinal, quem ousou ser Menipo, o que ri e zomba da morte e de seus mensageiros? Assim é que, à medida em que a construção se desenvolve, lenta, é bem verdade, a morte, já na condição de senhoria, marca presença, vezenquando te volteias, e o sujeito, sempre apto a prestar contas, a espia de hora em hora.

Mas antes de falar da casa como primeira morada, quero registrar a comoção perturbada que este poema me causou por seu forte poder de persuasão, isto é, a morte, sempre imaginada em sua riqueza metafísica e filosófica, por isso difícil de ser representada, quando se quer fugir à alegoria. Aqui ela é presentificada com tal intensidade que não se acaba a leitura do poema sem a certeza de sua presença concreta em nossas vidas. Certamente, a persuasão deriva das imagens materiais com que a poeta edifica o tema. Segundo Bachelard, "as imagens materiais transcendem (...) de imediato as sensações (...) As imagens materiais nos envolvem em uma afetividade mais profunda, por isso se enraízam nas camadas mais profundas do inconsciente. As imagens materiais substancializam um interesse. Essa substancialização condensa imagens numerosas, variadas, nascidas freqüentemente em sensações tão distantes da realidade presente que parece que todo um universo sensível está em potencial dentro da matéria imaginada (1990: 3)". Telhas, tijolos, madeiras, essas matérias tão concretas e elementares, mais as etapas da construção, vão-nos dando a sensação de que, ao edificar a vida, também estamos edificando a morte, tão certa, real e rija como uma telha e uma madeira.

Ao final do poema, quando casa faz par com começo e ambas personificam a "cara" da morte, "Casa e começo, tua cara, / A qualquer tempo te reconheço", a desconfiança ou o temor parece dissolver-se, porque, ao lado de "começo", "casa" recupera a imagem primordial do repouso, do renascimento e do conhecer-se a si mesmo, uma vez que a ambivalência da casa-corpo não pode ser negligenciada, 
conforme atesta Durand: "Os poetas, os psicanalistas, a tradição católica ou a sabedoria dos dogon fazem coro para reconhecer no simbolismo da casa um duplicado microcósmico do corpo material e do corpo mental" (2001: 243). Assim, o que somos está na nossa casa-corpo. A casa evoca a descida nas lembranças, o silêncio da reflexão ou o barulho da alegria, imagens que revelam a intimidade e o eterno recomeço, possível quando se desce às suas profundezas. Essa casa primordial, em que morte e vida se fundem no infindável "começo", é a casa onírica, que vive em nós, de que fala Bachelard: "A casa oniricamente completa é a única onde se pode viver os devaneios de intimidade em toda a sua variedade. Nela se vive só" (1990: 81). Assim concebida, a casa se torna o espaço feliz, o "centro paradisíaco"; habitá-la é voltar à casa da mãe, à terra natal, para começar. Vista como símbolo do trajeto psicológico, da construção de si, a casa é isomórfica da casa-corpo; por isso é preciso ver a casa como um lugar santo, assim como o corpo é um tabernáculo; é santo porque é refúgio, receptáculo, “o nosso centro propriamente dito" (DURAND, 2001: 246). Quando se deita para receber a morte, o sujeito-lírico a recebe como quem retorna ao lugar sagrado, protegido, como está no verso de outro poema: "E sonho pátios, guetos / E então te abraço". Sonhar assim a morte é sonhar uma morte feliz.

\section{A mandala}

A união de dois princípios opostos mas complementares, morte/vida, faz parte do desenvolvimento psíquico que, como a psicologia jungueana deixa claro, se exprime por símbolos. Dentre tantos símbolos de união, as mandalas se destacam por seu caráter de totalidade sagrada. Observando as mandalas desenhadas por doentes mentais, Jung escreve: "Os próprios pacientes quase nada podem dizer acerca do sentido simbólico das mandalas, mas se sentem fascinados por eles. Reconhecem que exprimem algo e que atuam sobre seu estado anímico subjetivo" (2002: 30) e, em páginas seguintes, completa: "O movimento circular também tem o significado moral da vivificação de todas as forças luminosas e obscuras da natureza humana, arrastando com elas todos os pares de opostos psicológicos, quaisquer que sejam. (33) Sonhar pátios e guetos é sonhar lugares fechados e, conseqüentemente, buscar a intimidade feliz e protegida, símbolo da totalidade que som a morte e seu caráter reintegrativo pode oferecer. Segundo Durand, o que sacraliza um lugar é seu fechamento (2001: 246), sua separação de um mundo ausente ao sagrado. Desta forma, "pátios e guetos" são centros revestidos 
da simbologia da casa e seu simbolismo de intimidade e totalidade, de paz e segurança. O abraço, símbolo mandálico por excelência, pela sua circularidade, evoca o refúgio natural, o tempo infinitamente suspenso e o retorno ao ventre feminino que, de alguma forma, está entrevisto no ato de deitar-se, formando uma constelação simbólica do repouso e da profundidade.

Durand associa o círculo, o centro "à grande constelação do Regime Noturno, que é a repetição. Como o espaço sagrado se reduplica indefinidamente, ele está associado à repetição primordial, ao tempo sagrado. Assim, morte é centro, princípio e fim intermináveis, por isso, razão do canto, que também se situa na esfera do sagrado:

Por que me fiz poeta?

Porque tu, morte, minha irmã, No instante, no centro de tudo o que vejo.

No nó de um ínfimo laço ... à minha volta

Te vejo

Centro, laço, volta... sempre de volta ao começo.

\section{O peixe}

A idéia da totalidade sagrada da morte que vai sendo elaborada ao longo do livro ainda se manifesta no poema em que a morte se apresenta tal como um peixe lilás e malva em águas claras. Esse peixe simbólico é o próprio sujeito poético que, no decurso da vida, vai sendo preparado para o mergulho definitivo:

E fios e linhas

Trançando máscaras

Para a minha cara:

Rubro mandala

Para um perfil. Então ajusto

Para o mergulho

Os principais símbolos desses versos estão ligados a uma circularidade sagrada. Da água já sabemos de sua dupla natureza, que ela mata e revivifica, conforme atesta estudiosos do imaginário, mas fiquemos com a opinião de Jung: “Uma vez que a água 
procurada e necessária representa um ciclo de nascimento e morte, todo processo, consistindo em morte e renascimento, significa a água divina." (2002: 104). De igual modo ambivalente é o símbolo do peixe, considerando a dupla natureza de sua origem bíblica: Leviatã, um ser alado das águas profundas que se desdobra em Beemot, o ser quadrúpede. Certamente, essas imagens desdobradas se completam, como o consciente e o inconsciente, a morte e a vida, conforme Jung: "neste sentido, Leviatã e particularmente Beemot representam estágios do desenvolvimento da consciência e portanto de uma assimilação do homem." (1986: 112). Essa dupla natureza que o peixe evoca está nos dois últimos versos: "Sou eu. Um peixe rubro / E um outro lilás e malva".

\section{O fio}

Nesses versos finais, ainda temos "fios" e "linhas", símbolos cíclicos, sobretudo do devir e do recomeço, sejam eles os fios de Penélope que prolongam o tempo ou a linha do destino fiada pelas Parcas. Esse tecido de fios e linhas, que gerou a mandala de sua máscara (outra forma de encarar o tempo), é o invólucro preservativo da intimidade, conforme atesta Durand: "Decerto o tecido, tal como o fio, é antes de mais um ligador (lien), mas é também ligação tranqüilizante, é símbolo de continuidade, sobredeterminado no inconsciente coletivo pela técnica "circular" ou rítmica da sua produção. O tecido é o que se opõe à descontinuidade, ao rasgo e à ruptura." (2001: 322) Dentro desse sentido de continuidade do tempo, as linhas trançadas, formando uma máscara-mandala, não deixam de evocar os invólucros preservadores da vida, como o das múmias e o das lagartas, separação e proteção ritualística e sagrada a partir da qual a vida poderia se renovar.

\section{O barco}

Para finalizar, ressalto uma última imagem de repouso, quietude e intimidade muito freqüente em Hilda Hilst, que expressa a situação atenuante de enfrentamento da morte: a imagem do barco. Se morrer é voltar para casa, a acolhedora terra-mãe, o barco sempre foi o primordial veículo dessa viagem. Como estamos falando de um retorno feliz, não evocamos a barca de Caronte ou os navios fantasmas, que transportam ou 
atormentam as almas. A barca de Hilda Hilst é a que conserva a alma para levá-la ao repouso eterno, barca agora convertida em poesia:

Uns barcos bordados

No último vestido

Para que venham comigo

As confissões, o riso

Quietude e paixão

De meus amigos. Porque guardei palavras

Numa grande arca

E as levarei comigo Uns barcos

Para a minha volta à Terra:

Este duro exercício

Para o meu espírito.

Todo exercício de retorno é duro, porque a viagem é uma travessia - lembremos da aventura de Ulisses - , mas também não nos esqueçamos da intimidade triunfante da barca, como aquela que conservou um destino feliz para Moisés e para o "nosso pai" em "A terceira margem do rio". Podemos dizer que o sujeito destes versos parte como o "audaz navegante" de Brejeirinha, aquele que vai descobrir outros lugares, no embalo e na proteção de uma barca-berço que reconduz à intimidade materna. Assim, essas duas naves, a vida e a morte, e uma só pessoa, navegam rumo às origens, ao centro-ovo, espaço em que o ciclo se fecha e recomeça indefinidamente, porque no ovo contém o universo, e na sua intimidade uterina a vida se renova, gerando o homunculusalquímico, esse ser emblemático disposto ao crescimento.

BACHELARD, Gaston. A terra e os devaneios do repouso. São Paulo: Martins Fontes, 1990.

DURAND, Gilbert. As estruturas antropológicas do imaginário. São Paulo: Martins Fontes, 2001.

HILST, Hilda. Da morte. Odes mínimas. São Paulo: Globo, 2003.

JUNG, C. G. Estudos alquímicos. Petrópolis, RJ: Vozes, 2002. Aion. Estudos sobre o simbolismo do si-mesmo. Petrópolis, RJ: Vozes, 1986.

ROCHA PITTA, Danielle Perin. Introdução à teoria do imaginário de Gilbert Durand. Rio de Janeiro: Atlântica Editora, 2005.

TURCHI, Maria Zaira. Literatura e antropologia do imaginário. Brasília: UnB, 2003. 